Papers and Proceedings of the Royal Society of Tasmania, Volume 110, 1976

(ms. received 8.4 .1975 )

\title{
ALBINISM IN THE TASMANIAN DEVIL
}

By Eric R. Guiler

Department of Zoology, University of Tasmania

(with one plate)

\section{ABSTRACT}

An albino Tasmanian devil (Sarcophitus harrisi (Boitard)) has been captured near Bothwell, Tasmania. This is the first record of albinism in the Dasyuroidea.

TEXT

The Tasmanian devil, Sareophizus harrisi (Boitard), usually has a general body colour of black, relieved in most individuals by white markings on the rump, chest and the lateral surface of the shoulders. The distribution of the white patches varies considerably, most devils having a white rump patch frequently combined with one or more of the other markings. In a small wild population the distribution and character of the marks is sufficiently characteristic to be used to identify individuals. Large white areas are very unusual and although a few devils may have large white rump patches this is most uncommon, the area of this mark usually being less than $12 \mathrm{sq} . \mathrm{cm}$.

Melanic devils were reported by Fleay (1946) who found that "nearly all" of the 19 devils captured at Jane River (West Coast) were melanic although data collected by Guiler (unpub. obs.) shows that $5.6 \%$ of another West Coast population of 263 animals were all black.

However, colour phases other than melanic and the variations noted above have not been reported until the recent capture by $\mathrm{Mr}$. J. $0^{\prime}$ Toole of an albino devil on Hunter-

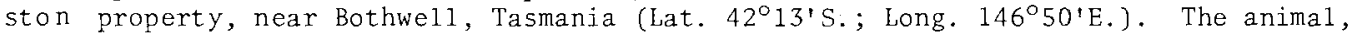
a fully grown male judged to be about 3-5 years old was white in colour, the only black being the rhinarium, the end of the snout as far posteriorly as the vibrissae, the mystacial vibrissae, and 3 small round spots, the largest being about $2 \mathrm{~cm}$. diameter, on the fronto-nasal region. The ears, eyes and their surrounding areas all were pink.

The animal was rounded up by sheep dogs near a fowl house where it had been believed to have killed hens. The devil was photographed and released but has not been recaptured.

Albinism is known to occur in a number of marsupials, the brush possum, Trichosurus vulpecuza (Kerr), and the rufous wallaby, Wazzabia mufogrisea (Desmarest), frequently showing this colour in wild Tasmanian populations. However, albinism or a white colour phase have not been reported from either the Dasyuroidea or the Dasyuridae, the groups to which the Tasmanian devil is assigned, and this colour phase must be very rare in this group of the marsupials.

I am indebted to Mr. R. O'Toole, formerly Assistant Ranger, National Parks and Wildife Service for this information and for the photographs taken by Mr. J. O'Toole. I also wish to thank the Director of the Service, Mr. P. Murrel1 for his co-operation. A colour photograph of the animal has been deposited in the Photographic Department of the University of Tasmania, File No. 74/11/89. 


\section{REFERENCE}

Fleay, D., 1946: On the trail of the marsupial wolf. Viet. Nat., 63, 129-35.

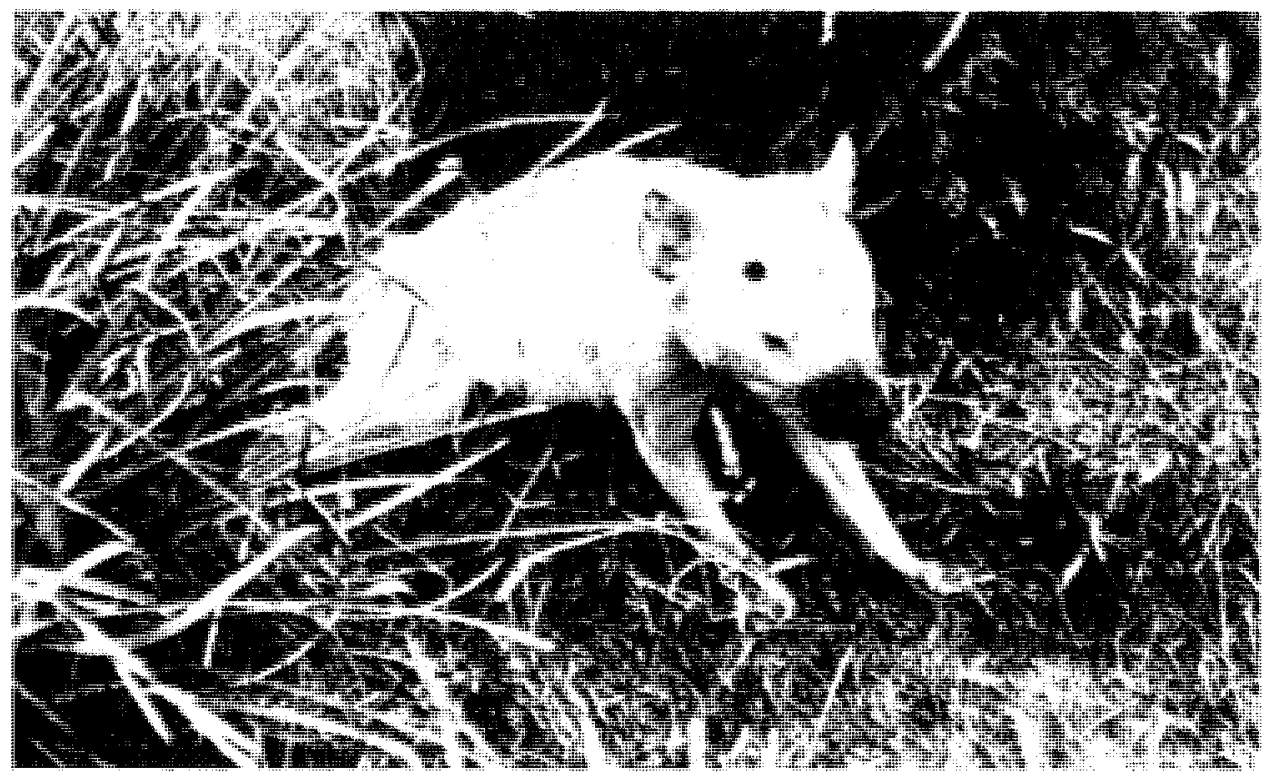

Albino Sarcophizus harmisi from Bothwe11, Tasmania, May, 1974. 